\title{
2006-2020: PROVIDING AN INTEGRATED INTERNATIONAL EXPERIENCE FOR UNDERGRADUATE ENGINEERING STUDENTS AT A SMALL INSTITUTION
}

\section{Eric Johnson, Valparaiso University}

Eric Johnson is the Paul and Cleo Brandt Professor of Engineering and an Associate Professor in the Electrical and Computer Engineering Department at Valparaiso University. His area of scientific research is design process methodologies and his teaching interests include introductory computer design courses and the development of international experiences for engineering students.

\section{Sarah DeMaris, Valparaiso University}

Sarah DeMaris is Professor of German and Director of the Kade-Duesenberg German House and Cultural Center at Valparaiso University. She teaches all levels of German language, literature, and culture and her research interests focus on late medieval Dominican history.

\section{Doug Tougaw, Valparaiso University}

Doug Tougaw is the Leitha and Willard Richardson Professor of Engineering and Department Chair of Electrical and Computer Engineering at Valparaiso University. His area of scientific research is nanotechnology, and his teaching interests include first-year courses and the interaction between engineering and business. 


\title{
Providing an Integrated International Experience for Undergraduate Engineering Students at a Small Institution
}

\begin{abstract}
This paper outlines the development of a new international engineering program at Valparaiso University. The Valparaiso University International Engineering Program (VIEP) is a five-year program that combines a major in one of four engineering fields with a major or minor in a foreign language. It also includes year-long residency in Germany. German was chosen as the first component of the program because of the university's German heritage and the abundance of German-related resources readily available through the university. The program allows students to gain a multi-cultural experience and German language proficiency along with technical engineering skills, and prepares them for careers in the international marketplace either in the US or abroad. The current status of the program is also detailed along with the advantages and challenges of creating such a program at a small, primarily liberal-arts institution.
\end{abstract}

\section{Introduction}

With the continued emphasis on globalization in industry, companies are seeking graduates in all areas who have some form of international experience. While liberal arts and business students are more likely to have these experiences, engineering students typically stay on campus during their undergraduate years. The main factors in keeping engineering students resident have been the inflexibility of the engineering curriculum and the lack of international opportunities for engineering students at most institutions [1]. Over the past ten years, however, this situation has begun to change as institutions see the value in an international experience for engineering undergraduates and are beginning provide various opportunities for them. ABET's new criteria have also helped engineering colleges by promoting engineering graduates who have the ability to work across linguistic and cultural boundaries.

The challenge to engineering institutions today is to determine what kind of international experience to offer. Typically the size and scope of the experience depends on the size of the institution. Many larger institutions offer a broad range of international opportunities over longer periods of time. As an example, one of the largest undergraduate international engineering programs is at the University of Rhode Island (URI). It offers a five-year, dual-degree program, which allows students to earn both a B.S. in Engineering and a B.A. in a foreign language (German, Spanish or French) [2]. Students enroll in appropriate courses for both majors, participate in a cooperative-education placement in overseas and live together in URI's International Engineering House. International companies, some of which have U.S. research and/or manufacturing plants near the university, are active partners in the program and provide cooperative education placements to the URI students. The program has grown quickly and currently enrolls over 175 students, a higher percentage of which are women and minority students than is average for engineering. 
URI takes a linguistically-integrated approach to the international experience, but many international experiences, usually with a smaller linguistic component, are offered by institutions across the country. Some of these include exchange trips to visit industries, tour academic facilities and hear lectures by local faculty [3][4]; design projects involving students working together from the U.S. and abroad [5]; study-abroad programs that focus on engineering students taking classes through international institutions [6][7][8]; and internships for engineers to work for an extended period of time, either with an international company or a U.S. company that does business overseas [9]. Some institutions even have separate departments that handle all international opportunities [10]. What most of these programs have in common is that they are offered at larger institutions. These institutions have the resources to develop and run international programs and can attract a significant number of students. The challenge for smaller institutions is to create the same or similar international experiences with available resources and still be cost-effective over the long term given the much lower number of students that will participate.

Valparaiso University falls into this small institution category. It is a private, independent university with a strong liberal arts component, which currently enrolls approximately 3000 undergraduate students, of whom 350 are enrolled in the College of Engineering. The university employs a full-time faculty of 264, with 21 faculty members in the College of Engineering. With such small numbers of both students and faculty, the challenge was to create an international experience that fulfilled the university's mission, attracted engineering students and was costeffective. One of three "directional themes" in Valparaiso University's Strategic Plan states that the university "will deliver a distinctive education that integrates fields of study ... [and] combines liberal with professional education, ... in order to form men and women who will flourish in an increasingly diverse and interconnected world." The international engineering experience named the Valparaiso International Engineering Program (VIEP) described in this paper responds to that directional theme by integrating the "hard skills" of an engineering education with the "soft skills" of cultural and linguistic fluency that will allow these engineers to work in an interconnected marketplace. It also provides exciting industrial and cultural experiences that will be attractive to engineering students and is cost-effective because a majority of the program's components are already in place at the university.

This paper will discuss the development of the VIEP from conception to its current form. It will also include perspectives of students in the program who are currently completing their year in Germany, how other small institutions can create a similar program, and the program's future directions.

\section{Program Development and Requirements}

The Valparaiso International Engineering Program development began as a joint collaboration between a faculty member in the Department of Foreign Languages and Literatures and a faculty member in the Department of Electrical and Computer Engineering. After a series of informal meetings about the development of some type of international experience for engineers, the two attended the 2002 International Colloquium on International Engineering Education hosted by the University of Rhode Island. This annual workshop provides a forum for faculty and administrators from engineering and foreign language departments, representatives of American 
and international companies, and other global institutions to discuss the importance of developing more international experiences for engineering students. A main portion of the workshop is the introduction of various models for international engineering programs at higher education institutions. After learning about the different models and talking with representatives from the various programs, the two faculty developed a list of generic components for the program at Valparaiso. These included:

- A significant foreign language component that continued throughout the student's undergraduate curriculum;

- An extended study-and work-abroad component (more than one semester) that would continue to enhance both the student's technical competency and language fluency;

- A cultural component, on the Valparaiso campus, that would allow the students to continue their language and cultural development.

From these components, a more detailed list of program requirements was developed. Some of these imitated other international engineering models while others were included because of unique resources available through the university. The first requirement is that students must enroll in one of the four engineering majors (civil, computer, electrical, or mechanical engineering) and take the full complement of courses required for that major. Additionally they must:

1) Complete a major or minor in German (depending on their beginning placement level in German) by taking at least one German course each semester beginning with the third semester;

2) Participate in the university's study-abroad program on the campus of the Hochschule fur Technik und Wirtschaft in Reutlingen, Germany during the fall of the fourth year;

3) Enroll, while in Germany, in a minimum of one mathematics, science, or engineering course taught in German at the Hochschule in Reutlingen;

4) Undertake a cooperative-education placement in industry during the February - July period following the study-abroad semester;

5) Reside in the Kade-Duesenberg German House and Cultural Center on the university campus for at least two semesters after achieving fourth-semester German language proficiency.

Requiring the students to complete a major or minor in German fulfilled the first generic component. Students with no prior German language courses would have to take at least seven German language classes to obtain a minor. The second generic component was fulfilled by the second, third and fourth requirements. The students would have the opportunity to spend an entire year in Germany. In the fall, they would participate in the university's long-established study abroad program where they would learn more about German and European culture and travel extensively. During this semester, they would also take at least one technical class in German from the Fachhochschule in Reutlingen. In the spring and summer, they would then coop with a German company where they could further develop both their technical and language skills. Finally, by living in the German House on campus, the students would fulfill the final general component, to further develop their language and cultural skills. To complete these requirements, a five-year plan of study was developed for the students as shown in Table 1. 
Table 1. Generic Five-Year Plan

\begin{tabular}{|c|c|c|c|}
\hline & Fall Semester & Spring Semester & Summer \\
\hline $\begin{array}{l}\text { Freshman } \\
\text { Year }\end{array}$ & $\begin{array}{l}\text { Engineering courses; add } \\
\text { one German course if } \\
\text { schedule allows. }\end{array}$ & $\begin{array}{l}\text { Engineering courses; add } \\
\text { one German course if } \\
\text { schedule allows. }\end{array}$ & \\
\hline $\begin{array}{l}\text { Sophomore } \\
\text { Year }\end{array}$ & $\begin{array}{l}\text { Engineering courses; one } \\
\text { German course. }\end{array}$ & $\begin{array}{l}\text { Engineering courses; one } \\
\text { German course. }\end{array}$ & \\
\hline Junior Year & $\begin{array}{l}\text { Engineering courses; one } \\
\text { German course. }\end{array}$ & $\begin{array}{l}\text { Engineering courses; one } \\
\text { German course. }\end{array}$ & \\
\hline Senior Year & $\begin{array}{l}\text { Study-abroad semester in } \\
\text { Reutlingen; at least one } \\
\text { German-language course in } \\
\text { math, science, or } \\
\text { engineering at FH- } \\
\text { Reutlingen (and/or next } \\
\text { semester). }\end{array}$ & $\begin{array}{l}\text { Cooperative education } \\
\text { placement in Reutlingen; } \\
\text { one course in engineering, } \\
\text { math, or science at FH- } \\
\text { Reutlingen (and/or last } \\
\text { semester). }\end{array}$ & $\begin{array}{l}\text { Cooperative } \\
\text { education } \\
\text { placement } \\
\text { continues. }\end{array}$ \\
\hline Year Five & $\begin{array}{l}\text { Engineering courses; one } \\
\text { German course. } \\
\text { Reside in the } \\
\text { Kade-Duesenberg House. }\end{array}$ & $\begin{array}{l}\text { Engineering courses; one } \\
\text { German course. } \\
\text { Reside in the } \\
\text { Kade-Duesenberg House. }\end{array}$ & \\
\hline
\end{tabular}

Given the generic plan, the next task was to create a suggested plan of study for each of the four disciplines offered (civil, computer, electrical and mechanical). After consultation with faculty members from the different departments, it was determined that there could be some overlap between the requirements for the engineering major and the German major, and some of the extra German courses could be used to fulfill general education or professional development requirements. This overlap cut back on the total number of credits students needed to complete the program. An example of the five-year plan of study for the Electrical Engineering students is given in Table 2. The German language courses are not linked to specific courses because the students can begin their German study at different levels.

The total number of credits for the electrical engineering plan of study is between 146.5 and 153 . It is important to note that this five-year plan assumes that students come into the program with no advanced standing. Most engineering students today, however, begin their college careers with some AP credits. If they do start with credits either in German or other subjects, they can then either begin taking German courses in their first year or start at a higher level of German.

What has helped with the development and implementation of the program is that most components described are already in place. The engineering and German programs at Valparaiso are fully developed and accredited. The College of Engineering has a well-established national cooperative-education program that will serve as a model for the international co-ops. The university's study-abroad program on the campus of the Hochschule in Reutlingen, Germany is in its $38^{\text {th }}$ year, and the Kade-Duesenberg German House and Cultural Center located on the campus is currently operating in its fifth year. 
Table 2. Suggested Plan of Study for Electrical Engineering

\begin{tabular}{|c|c|c|c|}
\hline \multicolumn{2}{|l|}{ Semester 1} & \multicolumn{2}{|l|}{ Semester 2} \\
\hline GE 100 - Fundamentals of Engineering & $3 \mathrm{Cr}$. & ECE 110 - Exploring Electrical Eng. & $2 \mathrm{Cr}$. \\
\hline GE 199 - Engineering Seminar & $0 \mathrm{Cr}$. & ECE 111 - Exploring ECE (lab) & $1 \mathrm{Cr}$. \\
\hline CORE 110 - The Human Experience & $5 \mathrm{Cr}$. & PHYS 142 - Electricity, Magnetism & $3 \mathrm{Cr}$. \\
\hline MATH 131 - Calculus I & $4 \mathrm{Cr}$. & CORE 115 - The Human Exp. & $5 \mathrm{Cr}$. \\
\hline PHYS 141 - Mechanics and Heat & $3 \mathrm{Cr}$. & MATH 132 - Calculus II & $4 \mathrm{Cr}$. \\
\hline PHYS 141L - Physics Lab I & $1 \mathrm{Cr}$. & PE 101-105 - Physical Education & $1 \mathrm{Cr}$. \\
\hline & $16 \mathrm{Cr}$. & & $16 \mathrm{Cr}$. \\
\hline Semester 3 & & Semester 4 & \\
\hline ECE 200 - Comp. Tech. For ECE I & $2 \mathrm{Cr}$. & ECE 201 - Comp. Tech. For ECE II & $2 \mathrm{Cr}$. \\
\hline ECE 221- Digital Systems Design & $3 \mathrm{Cr}$. & ECE 222- Advanced Logic Design & $3 \mathrm{Cr}$. \\
\hline ECE 251 - Algorithms and Prog. & $3 \mathrm{Cr}$. & ECE 261 - Linear Circuit Theory II & 3 Cr. \\
\hline ECE 261 - Linear Circuit Theory I & $3 \mathrm{Cr}$. & Math 253 - Calculus III & $4 \mathrm{Cr}$. \\
\hline Math 234 - Differential Equations & $4 \mathrm{Cr}$. & ENGL 200 - Literary Studies & $3 \mathrm{Cr}$. \\
\hline FLGR - German Course & 3-4 Cr. & FLGR - German Course & $3-4 \mathrm{Cr}$. \\
\hline & $-19 \mathrm{Cr}$. & & $18-19 \mathrm{Cr}$. \\
\hline Semester 5 & & Semester 6 & \\
\hline ECE 360 - Sampled Linear Systems & $3 \mathrm{Cr}$. & ECE 322 - Embedded Microcontroller & $3 \mathrm{Cr}$. \\
\hline ECE 340- Electronics I & $3 \mathrm{Cr}$. & ECE 341 - Electronics II & $3 \mathrm{Cr}$. \\
\hline Electrical Engineering Elective & $3 \mathrm{Cr}$. & ECE 365 - Prob. and Statistics for Eng & $3 \mathrm{Cr}$. \\
\hline Mathematics/Science Elective & $3 \mathrm{Cr}$. & GE 301 - Principles of Eng. Practice & $3 \mathrm{Cr}$. \\
\hline FLGR - German Course & 3-4 Cr. & FLGR - German Course & 3-4 Cr. \\
\hline & $-16 \mathrm{Cr}$. & & $15-16 \mathrm{Cr}$. \\
\hline Semester 7 - Reutlingen & & Semester 8 - Reutlingen & \\
\hline FLGR 204 - Repeat for credit & $4 \mathrm{Cr}$. & International Co-op & $0.5-3 \mathrm{Cr}$. \\
\hline ECON 290 - Topics in Economics & $3 \mathrm{Cr}$. & & \\
\hline ART 311 - European Art & $3 \mathrm{Cr}$. & & \\
\hline GS 390 - German Life and Culture & $3 \mathrm{Cr}$. & & \\
\hline EE Elective (in German from FH) & 3-4 Cr. & & \\
\hline & $-17 \mathrm{Cr}$. & & $0.5-3 \mathrm{Cr}$. \\
\hline Semester 9 & & Semester 10 & \\
\hline ECE 453 - Communication Systems & $3 \mathrm{Cr}$. & ECE 420- Electromagnetic Fields & $3 \mathrm{Cr}$. \\
\hline Electrical Engineering Elective & $3 \mathrm{Cr}$. & Electrical Engineering Elective & $3 \mathrm{Cr}$. \\
\hline Mathematics/Science Elective & $3 \mathrm{Cr}$. & Mathematics/Science Elective & $3 \mathrm{Cr}$. \\
\hline GE 497 - Senior Design Project I & $3 \mathrm{Cr}$. & Theology Elective & $3 \mathrm{Cr}$. \\
\hline FLGR - German Course & $3 \mathrm{Cr}$. & GE 498 - Senior Design Project II & $2 \mathrm{Cr}$. \\
\hline & -------- & FLGR - German Course & $3 \mathrm{Cr}$. \\
\hline & $15 \mathrm{Cr}$. & & $17 \mathrm{Cr}$. \\
\hline
\end{tabular}

\section{Program Implementation and Current Status}

Once the framework of the program was developed, the next phase was to generate interest among the current students in the College of Engineering and begin recruitment of prospective students. The two coordinators of the program realized early on that they would need financial 
help in accomplishing these tasks and began to identify grant possibilities. In the spring of 2004, the program was awarded a DAAD Group Study Visit grant that was instrumental in recruiting already-enrolled students. The grant paid for nine students, who had been taking German classes or had an interest in the program, to participate in a "Schnuppertour" ("snooping around tour"). This eight-day tour to Germany allowed the students to see the city where the study-abroad program was located, visit companies where they could be working and also spend time visiting cultural sites in southern Germany. Of the nine students who participated, three became members of the first VIEP class and four became members of the second class.

A number of different methods were used to recruit prospective students. These included the development of a brochure that could be distributed by the admissions office, letters to admitted engineering students who had taken German in high school and presentations at college or engineering visit days. Once the students began their freshman year on campus, they were also introduced to the program through the beginning engineering course that all students take and were invited to various VIEP events that were held during the academic year.

As the first group of three students continued taking their first three years of classes, there were other tasks that had to be accomplished before they spent their year in Germany. These included working with the Hochschule in Reutlingen to determine which technical classes the students could take, finding living arrangements for the students during their co-op assignment and making contacts with German engineering companies in the Reutlingen area. Since all of these tasks were located in Germany, the challenge to the program coordinators was to try to accomplish them in an effective manner. A unique opportunity arose, however, that helped not only with the completion of these tasks but also with assisting the first and second group of students as they spent their year in Germany. The directorship of the university's study-abroad program in Reutlingen was available and one of the coordinators applied for the position, was selected, and has moved to Germany for three years beginning in July 2004. This allowed him to spend the first year preparing for the first class of VIEP students and the next two years shepherding the first two classes through their stay in Germany.

During the first year in Germany, the coordinator was able to meet with faculty in the engineering departments at the Hochschule to translate descriptions of the engineering classes offered and determine possible classes that the students could take. He also made living arrangements on the Hochschule campus for the students during their co-op assignment and worked with the Hochschule to develop contacts within local engineering companies.

Currently, the first group of students is completing its year in Germany. This group consists of two electrical engineering students and one mechanical engineering student. Two of the three students have taken a significant number of German language courses while one has taken (to date) only the minimum five courses. Last fall and early this spring, they were in many of the university's normal study-abroad classes (4-5 courses taught in English) along with one technical class taught in German through the Hochschule. Students said that their biggest challenge was adjusting to how the course was structured and assessed. Classes in German higher education were different from what they were used to at Valparaiso. Lectures were not required; there were only class notes, not a textbook; there were very few assigned problems, which were not graded; and their entire grade for the course depended on how they performed on the final exam. 
Students said they to learn more independently than they had at Valparaiso. The one student who had had only four German courses, and was enrolled concurrently in her fifth, found it particularly challenging not only to follow what was happening in the course but also to perform well in the final exam, which was entirely in German.

The students also began seeking a co-op placement in early November. Before they came to Germany, they had prepared a resume and cover letter in German. In early November they sent these to contacts at engineering companies in the area. Companies were very excited about American students who also knew German and the students soon were offered interviews. During interviews the students spoke both German and English depending on their German language abilities. Within a month of beginning of their search, all three students received excellent offers both from industrial companies and research corporations. Their co-op positions will run from mid-February through the end of July and they will continue to live in the student dormitories on the campus of the Hochschule. One recommendation the students had for future VIEP students was to have them participate in mock-interviews at Valparaiso before coming to Germany. That experience would help them think about possible interview questions ahead of time and give them more confidence in their interviewing abilities, especially when speaking in a foreign language.

\section{Extension to other Universities}

Other educational institutions similar in size to Valparaiso that have a strong liberal arts component can replicate the international engineering program that has been described in this paper. The main challenge at smaller institutions, however, is that resources are scarce. At larger institutions there are separate "Departments of Global Engineering" or "International Co-op Programs" that develop and implement these types of programs. Smaller institutions usually don't have the money to create these new departments and instead have to utilize existing resources. More importantly, individual faculty members within engineering must be found to champion the program and put in the necessary hours to make the program successful.

There are a number of factors, however, that can minimize the amount of work needed to start such a program and maximize the possibility of success. The two most important are the commitment to the program by various departments throughout the institution (engineering, foreign languages, admissions, administration) and a connection to higher education institutions in countries where you want to base you first international experience. If these two items are in place, then developing a successful program involves looking at each institution's unique environment and determining which components of the program are most appropriate for it.

The first decision about a new international engineering program concerns the foreign language component. While some programs have tried to minimize the importance of learning or knowing another language because English is prevalent throughout the world, the authors feel strongly that the foreign language fluency of the students is as essential as their technical competence. Linguistic fluency is a key to cultural fluency and engineering students are more respected when they have a good grasp of the language and culture of the host country. Therefore, the foreign language component is a significant portion of the Valparaiso program. VIEP chose to begin with German because of the university's informal ties to German-descent Lutherans and the 
Lutheran churches. There were also significant resources in place at the university to support this decision. In addition to the German-language residential facility, the Kade-Duesenberg German House and Cultural Center, mentioned earlier, Valparaiso maintains two study-abroad programs in Germany, and supports a full academic program in German, including both a German major and minor and a faculty of three. Additionally, the choice seemed to make sense because Germany and Germans are often associated with excellence in technical fields; employment opportunities with German firms (a number of which operate in Indiana) seem secure. Many other institutions, however, have experienced a dramatic increase in the number of students who bring Spanish skills to the college or university level. For those institutions a similar engineering program that emphasizes Spanish language and Latin American or Peninsular cultural fluency might be more appropriate, especially if study-abroad programs and other contacts to Latin America or Spain have already been established. Likewise a given university might have a Spanish House on its campus, but not a German or French House.

The actual components that would be included in an international engineering program will depend on each institution. These components could range from short seminars or summersessions for students to year-long experiences that include taking multiple courses at a host institution and a co-op experience with a foreign company. When determining specific components to incorporate, institutions should take advantage of contacts or institutional programs already in place as much as possible. For example, if a co-op experience is wanted and an institution has an established engineering co-op program, coordinators can identify companies with which they have worked and which have offices overseas. If an institution doesn't have a working co-op program coordinators can tap advisory boards or the board of directors to find contacts with engineering companies. If coordinators want to have students take courses from a foreign institution and the institution has study-abroad programs, coordinators can look to the host institutions to identify if they have technical programs and what resources are in place for international students. Even if institutions don't have many resources in place, they can still find ways to incorporate the components they want into a program. For example, an institution that hosts students from other countries might utilize those students as cultural tutors in the program. On the other hand, an institution that offers language study without a study-abroad option might partner with another institution to allow students to enroll in an already-established program. By sharing or using already-in-place components to build an international engineering program, institutions can maintain costs at a reasonable level over the long-term and still produce a successful program.

\section{Future Directions of VIEP}

It was a conscious effort by the coordinators of VIEP to start with one language (German). This decision was not only the most resource-effective but was also the model followed by successful programs at larger schools such as the University of Rhode Island. While there is a temptation to try and attract new students by offering as many options as possible right away, the lessons learned from one successful program would save valuable time and resources when developing other programs, especially at smaller institutions.

At Valparaiso, the hope is that other options will follow after a few successful classes of students finish the current German program. There are a number of other language options at the 
university and those options, especially in French and Spanish, could be added to the program in the coming years.

If the program continues to grow and as other options are added, the VIEP will evolve and more administrative oversight will be needed. With more students and more options, a larger number of faculty will be needed to work with the program. This can be a problem at a small institution because of the small total number of faculty to begin with. Also, at this time, there is not an advisory board in place for the VIEP but one will be needed if the program expands. Finally, with a larger program, there will be a greater need for assessment. Others are beginning to look into assessment of engineering study abroad programs and their work will be leveraged if possible [11]. Even with additional administration needed, program growth is a positive outcome because in the end it allows more possible global experiences for engineering students.

\section{Conclusions}

This paper described a new international engineering program that has been developed at Valparaiso University. The five-year program seeks to prepare engineering students to work across cultural and linguistic boundaries by providing them the opportunity to combine their technical training in an engineering field with advanced study of German language and culture; a study-abroad experience in Germany; a four to six-month cooperative-education placement, also in Germany; and residency in the university's German-language-only residence hall. The program development and implementation has been successful to date with the first class of students currently completing their year in Germany. By using existing institutional resources, other small comprehensive institutions like Valparaiso could emulate many if not all of the components in the VIEP. If more institutions, both large and small, offered international engineering programs, engineering graduates in the U.S will have the technical ability and the cultural competence to be leaders in the global marketplace.

\section{References}

1. Website, International Engineering Program, The University of Rhode Island, http://www.uri.edu/iep/, January 2006.

2. DeWinter, U.J., "Science and Engineering Education Abroad: An Overview," Frontiers: The Interdisciplinary Journal of Study Abroad, fall 1997, Vol.3, No.2, pp.181-197.

3. Jones, D.K., Peng, A., Moreau-Jones, T.M., "International Exchange Program with China: The First-Year Experience of Engineering Technology Students," Proceedings of the 2005 Annual Conference and Exposition, Montreal, June 2005.

4. Budny, D. and Larkin, T. "Summer International Experience for First Year Students," Proceedings of the 2005 Annual Conference and Exposition, Portland, OR, June 2005.

5. Steffen, G.D., Hack, I. "Preliminary Investigation into Providing International Experience Through Study Abroad for Engineering Technology Students," Proceedings of the 2005 Annual Conference and Exposition, Portland, OR, June 2005.

6. Ellzey, J.L., Aanstoos, T.A., Schmidt, K.J., "Educating the Global Engineer: A New International Program at the University of Texas at Austin," Proceedings of the 2005 Annual Conference and Exposition, Portland, OR, June 2005. 
7. Eisenberg, S.R., Murray, J., and DeWinter U., "Developing a Study Abroad Opportunity for Engineering Undergraduates," Proceedings of the 2003 Annual Conference and Exposition, Nashville, TN, June 2003.

8. Mason, D.E., Merrill, J., Harichandran, R.S., Galishnikova, V., Maleck, T., Prestel, D. and Streng, P., "Innovation in a Large-Scale Study-Abroad Program in Engineering," Proceedings of the 2004 Annual Conference and Exposition, Salt Lake City, UT, June 2004.

9. Website, The International Co-op Program, The University of Cincinnati, http://www.eng.uc.edu/currentstudents/internationalprograms/, January 2006.

10. Website, International Program in Engineering, The University of Michigan, http://www.engin.umich.edu/ipe/index.html, January 2006.

11. Bettez, D.J., and Lineberry, G.T., “Assessing Engineering Students' Study Abroad Experience," Proceedings of the 2004 Annual Conference and Exposition, Salt Lake City, UT, June 2004. 